Pacific Journal of Mathematics

ON THE DISTRIBUTION OF $a$-POINTS OF A STRONGLY 


\title{
ON THE DISTRIBUTION \\ OF $a$-POINTS OF A STRONGLY \\ ANNULAR FUNCTION
}

\author{
Akio Osada
}

\begin{abstract}
This paper gives an example of a strongly annular function which omits 0 near an arc $I$ on the unit circle $C$ and which omits 1 near the complementary arc $C-I$. This example affirmatively answers the following question of Bonar: Does there exist any annular function for which we can find two or more complex numbers $w$ such that the limiting set of its $w$-points does not cover $C$ ?
\end{abstract}

1. Introduction. The purpose of this paper is to study the distribution of $a$-points of annular functions. We recall that a holomorphic function in the open unit disk $D:|z|<1$ is said to be annular [1] if there is a sequence $\left\{J_{n}\right\}$ of closed Jordan curves about the origin in $D$, converging out to the unit circle $C:|z|=1$, such that the minimum modulus of $f(z)$ on $J_{n}$ increases to infinity as $n$ increases. When the $J_{n}$ can be taken as circles concentric with $C, f(z)$ will be called strongly annular. Given a finite complex number $a$, the minimum modulus principle guarantees that every annular function $f$ has infinitely many $a$-points in $D$ and hence their limit points form a nonempty closed subset, say $Z^{\prime}(f, a)$, of $C$. On the other hand, by virtue of the Koebe-Gross theorem concerning meromorphic functions omitting three points, it follows from the annularity of $f$ that open sets $C-Z^{\prime}(f, a)$ and $C-Z^{\prime}(f, b)$ on the circle can not overlap if $a \neq b$ and consequently that the set of all values $a$ for which $Z^{\prime}(f, a) \neq C$ must be at most countable. Therefore we may well say such $a$ to be singular for $f$.

For this reason we will be concerned with the set $S(f)=$ $\left\{a: Z^{\prime}(f, a) \neq C\right\}$ in this paper. We denote by $|S(f)|$ the cardinality of $S(f)$ and then, from the simple fact observed above, we have that $0 \leqq|S(f)| \leqq N_{0}$, which in turn conversely tempt us to raise the following question: Given a cardinality $N\left(0 \leqq N \leqq N_{0}\right)$, can we find any annular function $f$ for which $|S(f)|=N$ ? ([1], [2]).

We know many examples of strongly annular functions such that $|S(f)|=0$ [4]. In particular if an annular function $f$ belongs to the MacLane class, i.e., the family of all nonconstant holomorphic functions in $D$ which have asymptotic values at each point of everywhere dense subsets of $C$, the set $S(f)$ becomes necessarily empty. As for $N=1$, Barth and Schneider [3] constructed an example of an annular function $f$ for which $|S(f)|=1$. The example involved in their construction, 
however, did not appear to be strongly annular. An example of a strongly annular $f$ with $|S(f)|=1$ was constructed independently by Barth, Bonar and Carroll [2] and the author [5]. The aim of this paper is to give an example of a strongly annular function $f$ for which $|S(f)|=2$.

2. For this purpose we consider a class of functions holomorphic in $D$. Let $I_{0}$ and $I_{1}$ be a pair of complementary open arcs on the unit circle $C$ and choose a Jordan arc $J_{J}$ connecting the end points of $I_{l}$, which is contained, except for its end points, in the open sector

$$
\left\{z: 0<|z|<1, z /|z| \in I_{l}\right\} \quad(j=0,1) .
$$

Further denote by $G_{j}$ the Jordan domain surrounded by $I_{j}$ and $J_{I}$ and consider

$S\left(G_{0}, G_{1}\right)=\left\{g \in H(D): g\right.$ is bounded away from 0 (or 1 ) in $G_{0}\left(\right.$ or $\left.\left.G_{1}\right)\right\}$

where $H(D)$ denotes the set of all functions holomorphic in $D$. In terms of this notation our purpose is in amount to find a strongly annular function which is locally a uniform limit of a sequence in $S\left(G_{0}, G_{1}\right)$. To construct such a function, we make essential use of the approximation theorem of Runge, which asserts that if $K$ is a compact set with connected complement relative to the plane and a function $g$ is holomorphic in an open set containing $K$, for any $\rho>0$, there is a polynomial $P$ such that

$$
|P(z)-g(z)|<\rho \quad(z \in K) .
$$

We call such $P$ an approximating polynomial with respect to the triple $(K, g, \rho)$. In our arguments to follow we may restrict ourselves to the special pair of $G_{0}$ and $G_{1}$ such that

$$
G_{0}=\{z=x+i y:|z|<1,2 x+|y|>1\} \quad \text { and } \quad G_{1}=\left\{z:-z \in G_{0}\right\}
$$

with no loss of generality, which serves to simplify the geometric formulation. Then the Runge theorem, in cooperation with our previous lemma, yields the following:

LEMMA. Let there be given positive numbers $\epsilon$ and $k$, numbers $a$ and $b$ with $0<a<b<1$, and a function $f$ in $S\left(G_{0}, G_{1}\right)$ (simply $S$ ), which is bounded in $G_{1}$. Then there exists a function $g$ in $S$, which is also bounded in $G_{1}$, such that

$$
|g(z)|>k \quad(|z|=b)
$$


and

$$
|g(z)-f(z)|<\epsilon \quad(|z| \leqq a) .
$$

Proof. We first divide the circle $|z|=b$ into 4 closed arcs as follows:

$$
\begin{array}{ll}
A_{0}=\left[-b i e^{i t}, b i e^{-i t}\right], & A_{1}=\left\{z:-z \in A_{0}\right\} \\
B_{0}=\left[b i e^{-u t}, b i e^{i t}\right], & B_{1}=\left\{z: \bar{z} \in B_{0}\right\} .
\end{array}
$$

Here $t(>0)$ should be chosen so small that we may apply our lemma [5] to an appropriately small open annular sector $R_{0}$, which is contained in

$$
\{z=x+i y: y>0,|z|>a, 2|x|+|y|<1\}
$$

and contains the $\operatorname{arc} B_{0}$. Set $R_{1}=\left\{z: \bar{z} \in R_{0}\right\}$.

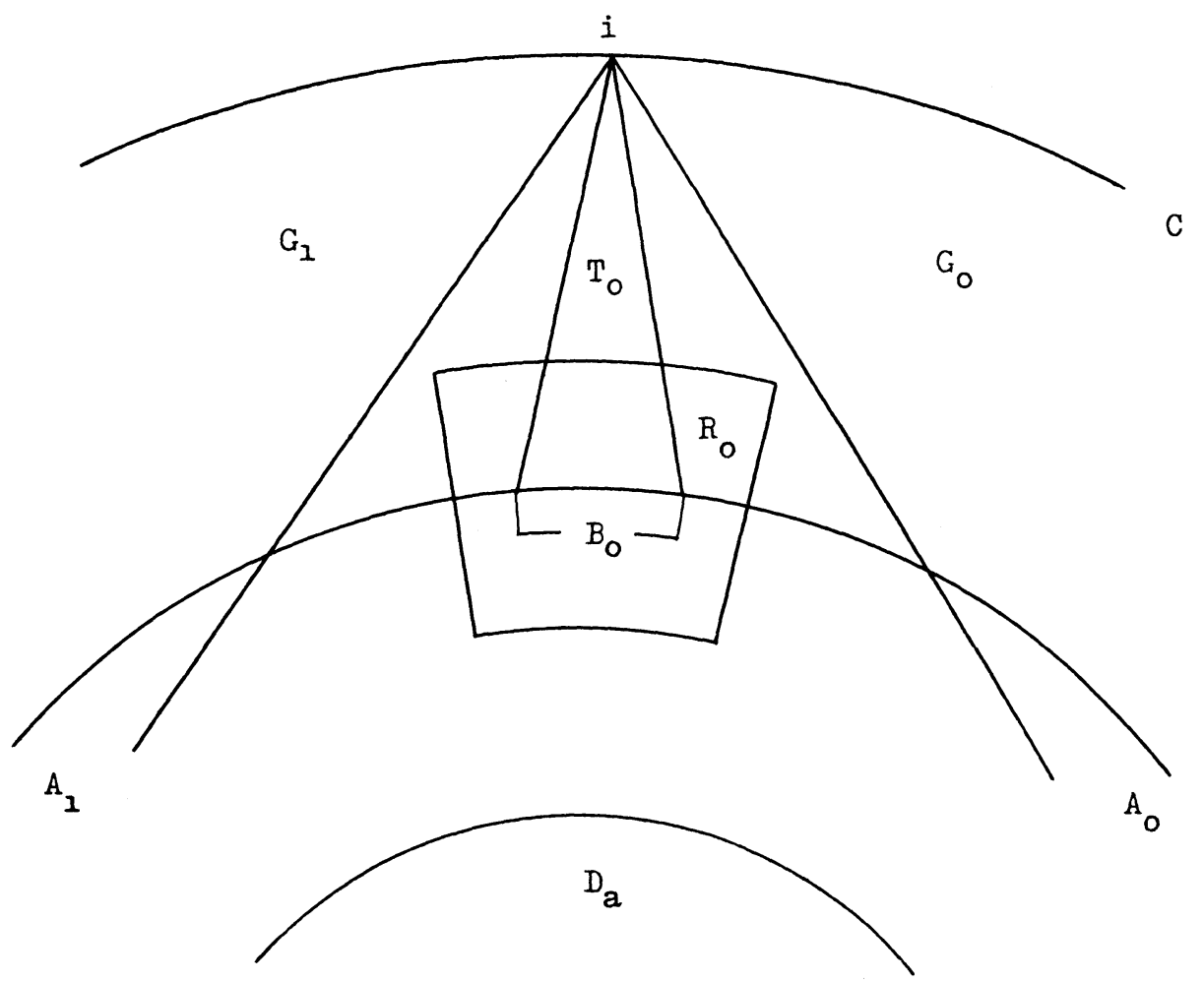

Next, to make use of the Runge theorem, we prepare two triples, which are defined, except for $c_{j}$ and $\rho_{i}$, by the following: 
(3)

$$
\left\{\begin{array}{ll}
K_{j}=\bar{G}_{,} \cup A_{\jmath} \cup A_{1-j} \cup \bar{D}_{a}, \bar{D}_{a}=\{z:|z| \leqq a\} & \\
g_{\jmath}(z)=0 & \left(z \in \bar{G}_{\jmath} \cup A_{\jmath} \cup \bar{D}_{a}\right) \\
g_{\jmath}(z)=c_{j}(>0) & \left(z \in A_{1-\jmath}\right)
\end{array} \quad(j=0,1) .\right.
$$

As for $c_{l}$ (or $\rho_{l}$ ) we shall later choose positive numbers large (or small) enough to satisfy our requirements. Obviously these definitions allow us to apply the Runge theorem to $\left(K_{i}, g_{l}, \rho_{l}\right)(j=0,1)$ and hence we can find an approximating polynomial $P_{\jmath}$. On the other hand, if necessary, adding a small vector we may assume that $f(z) \neq 0,1$ on the circle $|z|=b$. Combining these functions, define a function $F$ holomorphic in $D$ by

$$
F(z)=\left\{(f(z)-1) \exp \left(P_{0}(z)\right)+1\right\} \exp \left(P_{1}(z)\right) .
$$

Then carefully observing (3) and suitably choosing values of $c_{j}$ and $\rho_{j}$, we can conclude that the function $F$ is a member of $S$, bounded in $G_{1}$ and has the following properties:

$$
\begin{array}{ll}
|F(z)|>2 k & \left(z \in\{z:|z|=b\}-B_{0}-B_{1}\right) \\
|F(z)-f(z)|<\epsilon / 2 & \left(z \in \bar{D}_{a}\right) .
\end{array}
$$

In addition it may be supposed that $F$ does not vanish on $B_{0} \cup B_{1}$.

Thus the last step in our construction of $g$ is to make $|F(z)|$ large on the remaining arcs $B_{0}$ and $B_{1}$ without losing the properties described above of $F$. Given $c_{2}>0$ and $\rho_{2}>0$, applying our lemma [5] to the annular sectors $R_{0}$ and $R_{1}$ previously chosen, and successively using the standard "pole sweeping" method for the resulting rational functions, we can find a holomorphic function $H_{1}$ in $D$ such that

$$
\begin{array}{ll}
\left|H_{j}(z)\right|>c_{2} & \left(z \in B_{l}\right), \\
\operatorname{Re} H_{l}(z)>-\rho_{2} & \left(z \in R_{j} \cap\{z:|z|=b\}-B_{l}\right)
\end{array}
$$

and

$$
\left|H_{j}(z)\right|<2 \rho_{2} \quad\left(z \in D-T_{j}\right)
$$

where $T_{0}$ (or $T_{1}$ ) denotes an appropriate "pole sweeping route" ending at $z=i$ (or $-i$ ) which is contained in

$$
E_{0}=\{z=x+i y: y>0,|z|>b, 2|x|+|y|<1\}
$$


(or $E_{1}=\left\{z: \bar{z} \in E_{0}\right\}$ ) (see Figure 1). Using these functions and $F$ defined above, set

$$
F(z)\left\{1+H_{0}(z)\right\}\left\{1+H_{1}(z)\right\}=g(z) .
$$

Since $F$ does not vanish on $B_{0} \cup B_{1}$, if we appropriately choose a large (or small) positive number as a value of $c_{2}$ (or $\rho_{2}$ ), by virtue of (4) and (5) together with (6), (7) and (8), we can show that the function $g$ belongs to the class $S$, is bounded in $G_{1}$ and further satisfies (1) and (2). This proves Lemma.

3. The following result is immediate from Lemma in 2 .

THEOREM. Let $\left\{r_{n}\right\}$ and $\left\{k_{n}\right\}$ be two sequences of positive numbers with $r_{n} \uparrow 1$ and $1<k_{n} \uparrow+\infty$. Then there exists a function $f$, which is locally a uniform limit of a sequence in $S$ and which furthermore satisfies that $|f(z)| \geqq k_{n}$ on the circle $|z|=r_{n}$.

Proof. It is sufficient to construct a sequence $\left\{f_{n}(z)\right\}$ in $S$ such that

$$
\begin{array}{ll}
\left|f_{n}(z)\right|>k_{,} \text {if } 1 \leqq j \leqq n & \left(z \in C_{j}=\left\{z:|z|=r_{j}\right\}\right), \\
\left|f_{n}(z)-f_{n-1}(z)\right|<\epsilon_{n-1} & \left(|z| \leqq r_{n-1}, n \geqq 2\right)
\end{array}
$$

and

$$
f_{n} \quad \text { is bounded in } G_{1}
$$

where $\left\{\epsilon_{n}\right\}$ is a preassigned sequence of positive numbers with $\Sigma \epsilon_{n}<+\infty$. In order to construct $\left\{f_{n}\right\}$ inductively, let $f_{1}(z)=2 k_{1}$ and suppose that $f_{1}, \cdots, f_{n-1}$ have already been defined. In Lemma in 2 , on setting $f=f_{n-1}, a=r_{n-1}, b=r_{n}, k=k_{n}$ and $\epsilon=\min \left\{\epsilon_{n-1}, m_{1}, \cdots, m_{n-1}\right\}$ where $m_{j}=\min \left\{\left|f_{n-1}(z)\right|-k_{j}: z \in C_{j}\right\}$, we can find a function $f_{n}$ in $S$ satisfying (9), (10) and (11). Thus we obtain a sequence $\left\{f_{n}\right\}$ in $S$, which, by virtue of (10), converges uniformly on any compact subset of $D$. Obviously its limit $f$ is a desired function in Theorem. Hence our proof is complete.

The author is grateful for the valuable comments and suggestions of the referee.

\section{REFERENCES}

1. F. Bagemihl and P. Erdös, A problem concerning the zeros of a certain kind of holomorphic function in the unit circle, J. Reine Angew. Math., 214/215 (1964), 340-344. 
2. K. Barth, D. D. Bonar and F. W. Carroll, Zeros of strongly annular functions, Math. Z., 144 (1975), 175-179.

3. K. Barth and W. Schneider, On a problem of Bagemihl and Erdös concerning the distribution of zeros of an annular function, J. Reine Angew. Math., 234 (1969), 179-183.

4. D. D. Bonar, On annular functions, VEB Deutscher Verlag der Wissenschaften, Berlin, (1971).

5. A. Osada, On the distribution of zeros of a strongly annular function, Nagoya Math. J., 56 (1974), 13-17.

Received January 28, 1976 and in revised form June 6, 1976.

Gifu College of Pharmacy

MITAHORA, GiFU, JAPAN 


\section{PACIFIC JOURNAL OF MATHEMATICS}

\section{EDITORS}

RichaRd ARENS (Managing Editor)

University of California

Los Angeles, CA 90024

\section{R. A. Beaumont}

University of Washington

Seattle, WA 98105

C. C. Moore

University of California

Berkeley, CA 94720
J. DugunduI

Department of Mathematics

University of Southern California

Los Angeles, CA 90007

R. Finn AND J. Milgram

Stanford University

Stanford, CA 94305

\section{ASSOCIATE EDITORS}
E. F. BECKENBACH
B. H. NeumanN
F. WOLF
K. YoshidA

\section{SUPPORTING INSTITUTIONS}

UNIVERSITY OF BRITISH COLUMBIA

CALIFORNIA INSTITUTE OF TECHNOLOGY

UNIVERSITY OF CALIFORNIA

MONTANA STATE UNIVERSITY

UNIVERSITY OF NEVADA

NEW MEXICO STATE UNIVERSITY

OREGON STATE UNIVERSITY

UNIVERSITY OF OREGON

OSAKA UNIVERSITY

\author{
UNIVERSITY OF SOUTHERN CALIFORNIA \\ STANFORD UNIVERSITY \\ UNIVERSITY OF HAWAII \\ UNIVERSITY OF TOKYO \\ UNIVERSITY OF UTAH \\ WASHINGTON STATE UNIVERSITY \\ UNIVERSITY OF WASHINGTON \\ AMERICAN MATHEMATICAL SOCIETY
}

The Supporting Institutions listed above contribute to the cost of publication of this Journal, but they are not owners or publishers and have no responsibility for its contents or policies.

Mathematical papers intended for publication in the Pacific Journal of Mathematics should be in typed form or offset-reproduced (not dittoed), double spaced with large margins. Underline Greek letters in red, German in green, and script in blue. The first paragraph or two must be capable of being used separately as a synopsis of the entire paper. Items of the bibliography should not be cited there unless absolutely necessary, in which case they must be identified by author and Journal, rather than by item number. Manuscripts, in duplicate, may be sent to any one of the four editors. Please classify according to the scheme of Math. Reviews, Index to Vol. 39. All other communications should be addressed to the managing editor, or Elaine Barth, University of California, Los Angeles, California, 90024.

100 reprints are provided free for each article, only if page charges have been substantially paid. Additional copies may be obtained at cost in multiples of 50 .

The Pacific Journal of Mathematics is issued monthly as of January 1966. Regular subscription rate: $\$ 72.00$ a year (6 Vols., 12 issues). Special rate: $\$ 36.00$ a year to individual members of supporting institutions.

Subscriptions, orders for back numbers, and changes of address should be sent to Pacific Journal of Mathematics, 103 Highland Boulevard, Berkeley, California, 94708.

PUBLISHED BY PACIFIC JOURNAL OF MATHEMATICS, A NON-PROFIT CORPORATION

Printed at Jerusalem Academic Press, POB 2390, Jerusalem, Israel. 


\section{Pacific Journal of Mathematics}

Vol. 68, No. 2

April, 1977

William Allen Adkins, Aldo Andreotti and John Vincent Leahy, An analogue of Oka's theorem for weakly normal complex spaces ........

Ann K. Boyle, M. G. Deshpande and Edmund H. Feller, On nonsingularly

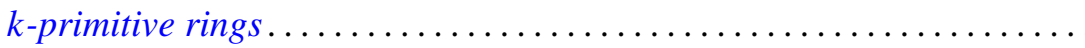

Rolando Basim Chuaqui, Measures invariant under a group of

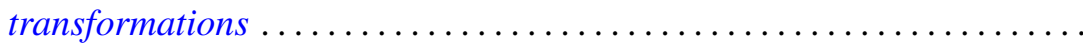

Wendell Dan Curtis and Forrest Miller, Gauge groups and classification of bundles with simple structural group .......................

Garret J. Etgen and Willie Taylor, The essential uniqueness of bounded nonoscillatory solutions of certain even order differential equations

Paul Ezust, On a representation theory for ideal systems

Richard Carl Gilbert, The deficiency index of a third order operator ........

John Norman Ginsburg, $S$-spaces in countably compact spaces using Ostaszewski's method.

Basil Gordon and S. P. Mohanty, On a theorem of Delaunay and some

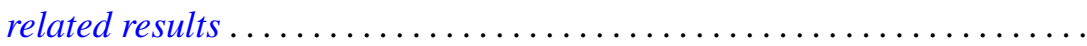

Douglas Lloyd Grant, Topological groups which satisfy an open mapping

theorem.

Charles Lemuel Hagopian, A characterization of solenoids

Kyong Taik Hahn, On completeness of the Bergman metric and its

subordinate metrics. II .

G. Hochschild and David Wheeler Wigner, Abstractly split group extensions.

Gary S. Itzkowitz, Inner invariant subspaces ...............

Jiang Luh and Mohan S. Putcha, A commutativity theorem for

non-associative algebras over a principal ideal domain.

Donald J. Newman and A. R. Reddy, Addendum to: "Rational approximation of $e^{-x}$ on the positive real axis".....

Akio Osada, On the distribution of a-points of a strongly annular function ....

Jeffrey Lynn Spielman, A characterization of the Gaussian distribution in a Hilbert space. .

Robert Moffatt Stephenson Jr., Symmetrizable-closed spaces ...

Peter George Trotter and Takayuki Tamura, Completely semisimple inverse $\Delta$-semigroups admitting principal series . . . . . . . .

Charles Irvin Vinsonhaler and William Jennings Wickless, Torsion free abelian groups quasi-projective over their endomorphism rings...

Frank Arvey Wattenberg, Topologies on the set of closed subsets ... 